\title{
Corrosion of Steel Pipelines Transporting Hydrocarbon Condensed Products, Obtained from a High Pressure Separator System: A Failure Analysis Study
}

\author{
Gerardo Zavala Olivares*, Mónica Jazmín Hernández Gayosso \\ Instituto Mexicano Del Petróleo. Eje Central Lázaro Cárdenas Norte,Col. San Bartolo Atepehuacan, C.P., México \\ D.F., México \\ Email: "gzavala@imp.mx
}

Received 11 July 2015; accepted 20 August 2015; published 24 August 2015

Copyright @ 2015 by authors and Scientific Research Publishing Inc.

This work is licensed under the Creative Commons Attribution International License (CC BY).

http://creativecommons.org/licenses/by/4.0/

$$
\text { (c) (i) Open Access }
$$

\begin{abstract}
In this paper, the corrosion of steel pipelines transporting hydrocarbon condensed products was studied. Different activities of sampling and analysis were carried out to diagnose the failure causes and to establish a control system for the corrosion problem. The combination of three types of corrosion, including erosion corrosion, galvanic corrosion and microbiologically induced corrosion, was synthetically considered. A serial of experiments were designed to research those types of corrosion. This type of failure was observed in characteristics sites of the pipeline, mainly in direction changes and welding joints. Additionally, localized corrosion was observed in the inner steel wall and distributed along the pipeline, although a tendency was not detected.
\end{abstract}

\section{Keywords}

Erosion Corrosion, Galvanic Corrosion, Microbiologically Induced Corrosion

\section{Introduction}

Nowadays, hydrocarbon transportation in the oil industry is accomplished through pipelines. Huge volume of gas and liquid can be transported in an efficient and safe way. During the gas-oil separation processes, the operational parameters may come out of control and some operational problems may occur, including corrosion failures.

\footnotetext{
${ }^{*}$ Corresponding author.
}

How to cite this paper: Olivares, G.Z. and Gayosso, M.J.H. (2015) Corrosion of Steel Pipelines Transporting Hydrocarbon Condensed Products, Obtained from a High Pressure Separator System: A Failure Analysis Study. Materials Sciences and Applications, 6, 760-772. http://dx.doi.org/10.4236/msa.2015.68078 
A corrosion problem was observed in a 2 inches diameter steel pipeline, transporting hydrocarbon condensed products obtained from a high pressure separator system located in an offshore platform in the Gulf of Mexico. This situation generated critical conditions that favored the pipeline corrosion development and resulted in some leaks. Initially, it was presumed that the failure could be caused by effect of microbiologically induced corrosion. However, as the failures did not exhibit a regular pattern, it was considered that others types of corrosion were involved in the problematic. According to this, several activities, mainly directed to diagnose the failure conditions, were carried out [1]-[3].

Therefore, it was intended to diagnose the causes for the corrosion failures in the pipeline at the output of the high pressure separator system. With this, recommendations for corrosion control can be made.

\section{Activities}

The activities carried out were divided in two stages: Stage 1 focused on the characterization of the hydrocarbon streams, at the sites where the leaks occurred. This was in order to determine the main corrosive agents in the system. Stage 2 directed to analyze the corrosion products at the metal surface, as well as the type and morphology of the corrosion process. With these activities, the causes for the corrosion failures could be established.

\subsection{Stage 1}

Two monitoring points were selected, considering streams that were incorporated to the system that exhibited the leak. These points were named P-I and P-II.

Field activities: Initially, an inspection of the system was carried out, to identify the monitoring points and to collect both, water and condensed products. Four samples were taken from the monitoring points, leaving a gap of 24 hours between each sampling [4].

For water samples, different parameters were measured in situ: Temperature, Pressure, $\mathrm{pH}, \mathrm{O}_{2}$ content, $\mathrm{CO}_{2}$ content, $\mathrm{H}_{2} \mathrm{~S}$ content, conductivity and presence of sulfate reducing bacteria (SRB) [5].

Laboratory activities: Physical and chemical analysis were carried out to water samples. The analysis for the condensed products samples were: hydrocarbon characterization, $\mathrm{O}_{2}$ content, $\mathrm{CO}_{2}$ content, $\mathrm{H}_{2} \mathrm{~S}$ content, humidity, Sulfur compounds [6].

\subsection{Stage 2}

A leak occurred in a 2 inches steel pipeline transporting hydrocarbon condensed products. A section of the pipeline, where the failure occurred, was cut and replaced. The sample was prepared and sent to the laboratory, for its respective analysis. Once the sample was at the laboratory, the failure was located and corrosion products were obtained from the adjacent area. Different analysis were carried out, including X-ray diffraction and fluorescence, Mössbauer spectroscopy, surface analysis, hardness, chemical analysis and identification of sulfate reducing bacteria, among others.

\section{Results and Discussion}

\subsection{Stage 1}

\subsubsection{Water Analysis}

During the sampling procedure, it was observed that the hydrocarbon obtained exhibited high water content. Water is necessary when a corrosion process is taking place and the extent of the damage depends on its corrosive characteristics.

In all cases, the samples were identified as condensation water, with low conductivity. However, the Langelier index indicated a corrosive tendency for all samples [7]. Values between -3 and -5 were observed, as shown in Figure 1. This situation implies that water may become very aggressive to the metallic structures.

Additionally, it must be indicated that the water corrosiveness for these systems was also related to the content of dissolved gases, including $\mathrm{H}_{2} \mathrm{~S}, \mathrm{CO}_{2}$ and $\mathrm{O}_{2}$. For this case, the $\mathrm{H}_{2} \mathrm{~S}$ concentration was between 5 and 45 ppm, $\mathrm{O}_{2}$ between 0 and $2.6 \mathrm{ppm}$ and $\mathrm{CO}_{2}$ between 28 and $75 \mathrm{ppm}$ (Figures 2-4). The presence of these gases in water and hydrocarbon represents a corrosion risk for the metallic structures, and a prevention system must be considered [8]-[10]. 


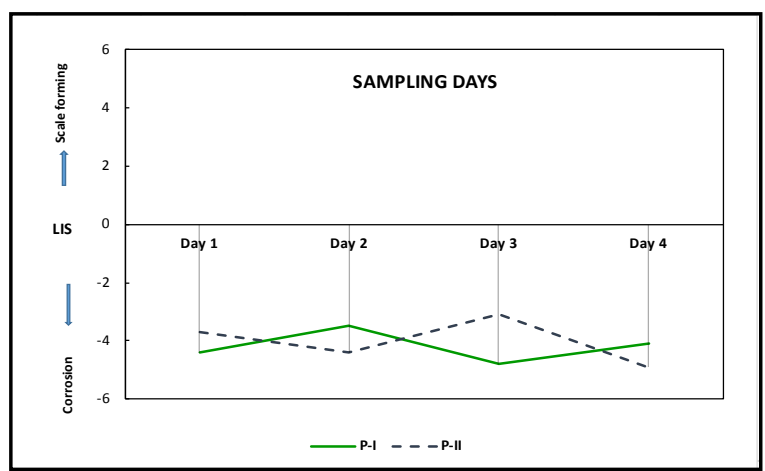

Figure 1. Langelier Index Stability (LIS) for water samples.

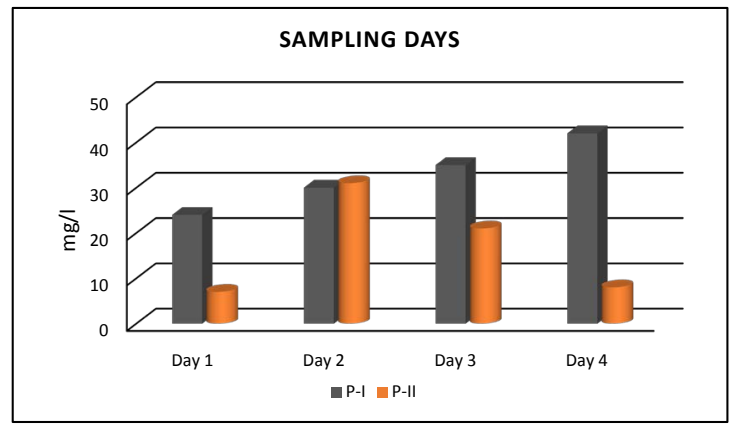

Figure $2 . \mathrm{H}_{2} \mathrm{~S}$ concentration in water samples.

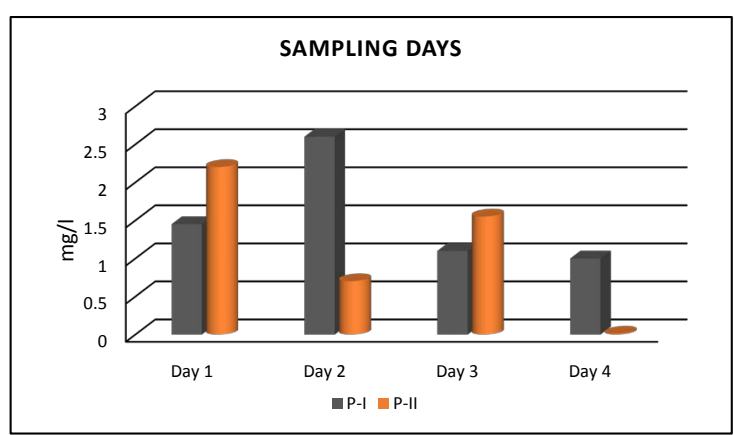

Figure $3 . \mathrm{O}_{2}$ concentration in water samples.

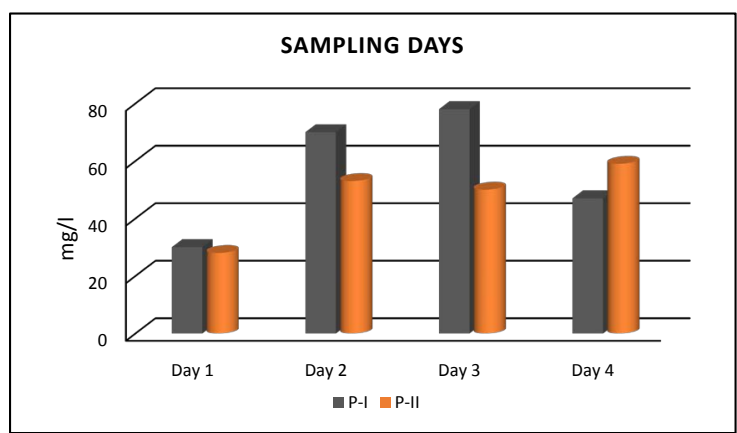

Figure 4. $\mathrm{CO}_{2}$ concentration in water samples.

It is important to point out that the variations observed between the analyzed samples for P-I and P-II are slight; therefore, their corrosive tendency is similar. At the same time, the $\mathrm{O}_{2}$ and $\mathrm{CO}_{2}$ contents exhibit some 
differences that are considered as normal, due to the fluid characteristic variations.

One of the parameters that present bigger differences is the $\mathrm{H}_{2} \mathrm{~S}$ content. Here, an increase with time for samples taken from P-I was observed, reporting values between 20 and $40 \mathrm{mg} / \mathrm{l}$. For samples taken from P-II, lower values were reported, in the range of 5 and $30 \mathrm{mg} / \mathrm{l}$. It must be noted that the concentration of corrosive gases in water depends upon the general characteristics of the hydrocarbon, specially pressure and temperature. Therefore, the results allow establishing the presence of corrosive gases in the analyzed water samples.

In the same way, it may be indicated that iron content in the water samples is a reference to establish whether the corrosion process is taking place or not, and to determine the necessity of a control system [11]. For this case, both fluids P-I and P-II exhibited corrosive characteristics, although a difference in the iron content could be observed (Figure 5).

The samples taken in P-I had values around $0.5 \mathrm{ppm}$, while the samples from P-II reported values between 3.3 and $4.2 \mathrm{ppm}$.

These differences can be related to some specific system conditions and parameters:

- Chemical composition and/or material resistance;

- Temperature;

- Flow;

- System life time;

- Addition of chemicals, such as corrosion inhibitors, scale inhibitors, among others;

- Process efficiency.

On the other hand, the presence of microorganisms was determined in all water samples. Sulfate reducing bacteria populations around 100 bacteria $/ \mathrm{cm}^{3}$ were observed. This situation is considered as a potential problem of localized corrosion.

\subsubsection{Hydrocarbon Analysis}

The fluid is mainly composed of light hydrocarbons, such as methane, ethane and propane. This is considered as a normal situation. However, there were some corrosive gases in the hydrocarbon composition. Contents of $\mathrm{H}_{2} \mathrm{~S}$, $\mathrm{CO}_{2}$ and $\mathrm{O}_{2}$ were determined, as shown in Figure 6 and Figure 7. Here, both points P-I and P-II, show similar gases proportion.

Considering their effect on the corrosion processes, these gases represent a continuous source of corrosive compounds for the aqueous phase. Once the products are consumed in the reaction, the gases dissolve in water to keep the corrosion process going on.

According to the fluid characteristics, the parameters identified as the responsible for the corrosion process in the systems are:

1) Water content;

2) Presence of dissolved corrosive gases;

3) Presence of microorganisms, mainly Sulfate reducing bacteria (SRB);

\subsection{Stage 2}

The analyzed sample was taken at the exit of a high pressure separator, as shown in Figure 8. The pipeline had

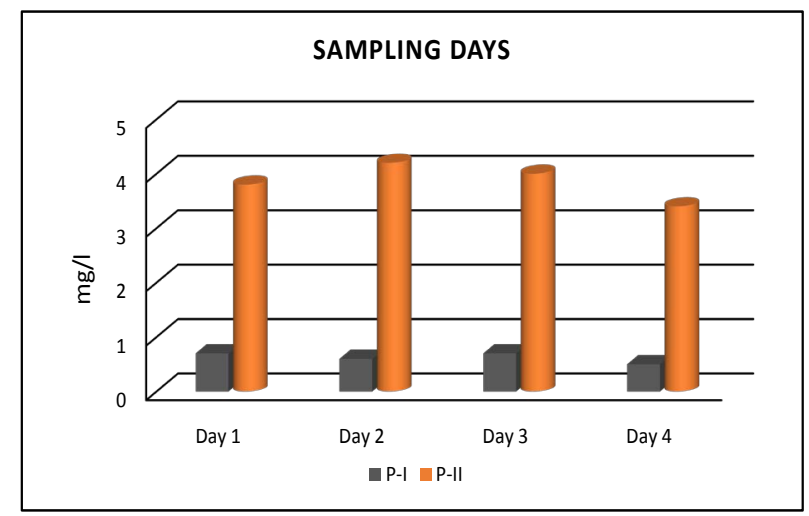

Figure 5. $\mathrm{Fe}^{2+}$ Concentration in water samples. 


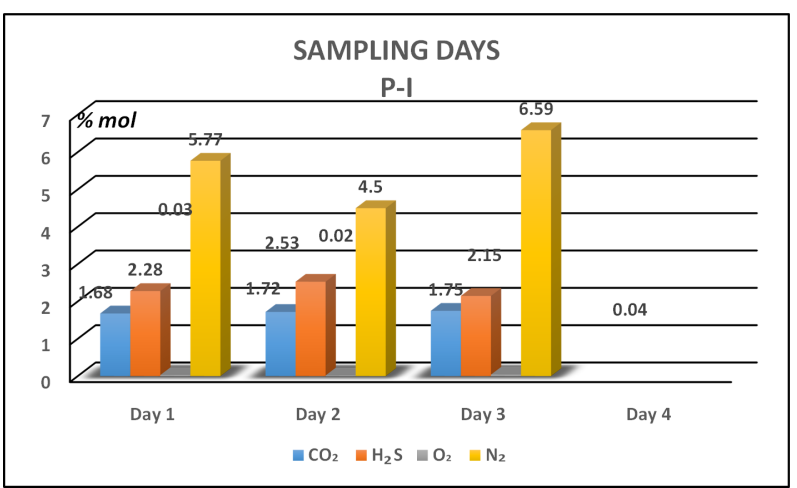

Figure 6. Concentration of corrosive gases in hydrocarbon composition (P-I).

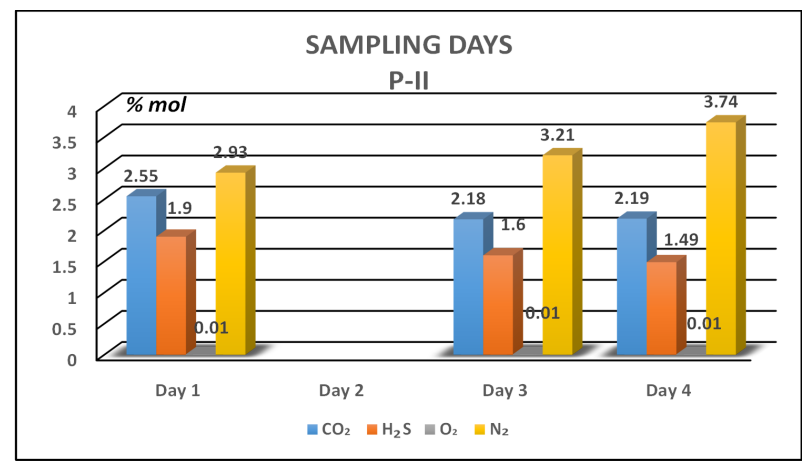

Figure 7. Concentration of corrosive gases in hydrocarbon composition (P-II).

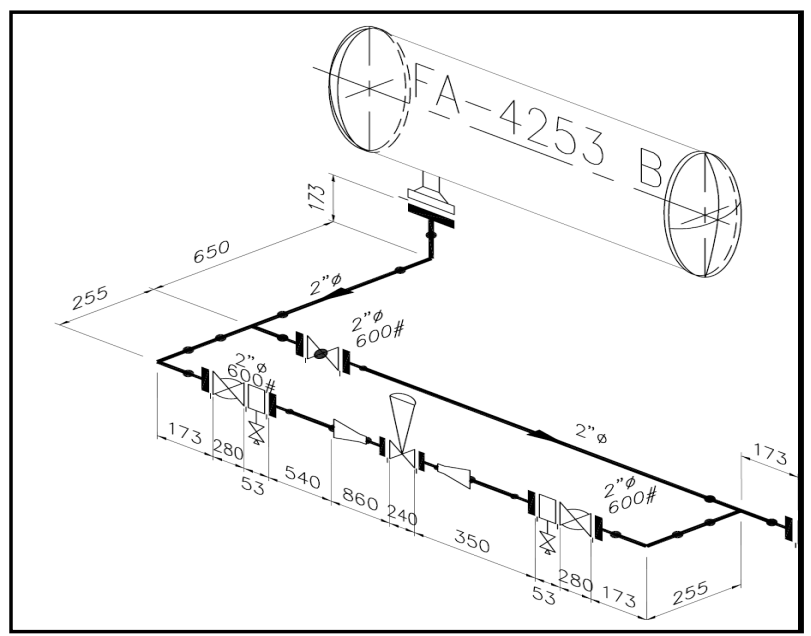

Figure 8. Diagram of the high pressure separator system.

closed valves at the ends and nitrogen gas was bubbled inside, to assure anoxic conditions.

The failure was located at the welding joint with the first elbow, according to the fluid flow and at the 6 technical hours position, as shown in Figure 9.

The sample analyses were carried out as follows.

\subsubsection{Microbiological Analysis}

The presence of sulfate reducing bacteria (SRB) was identified inside the pipeline, next to the failure and in dif- 

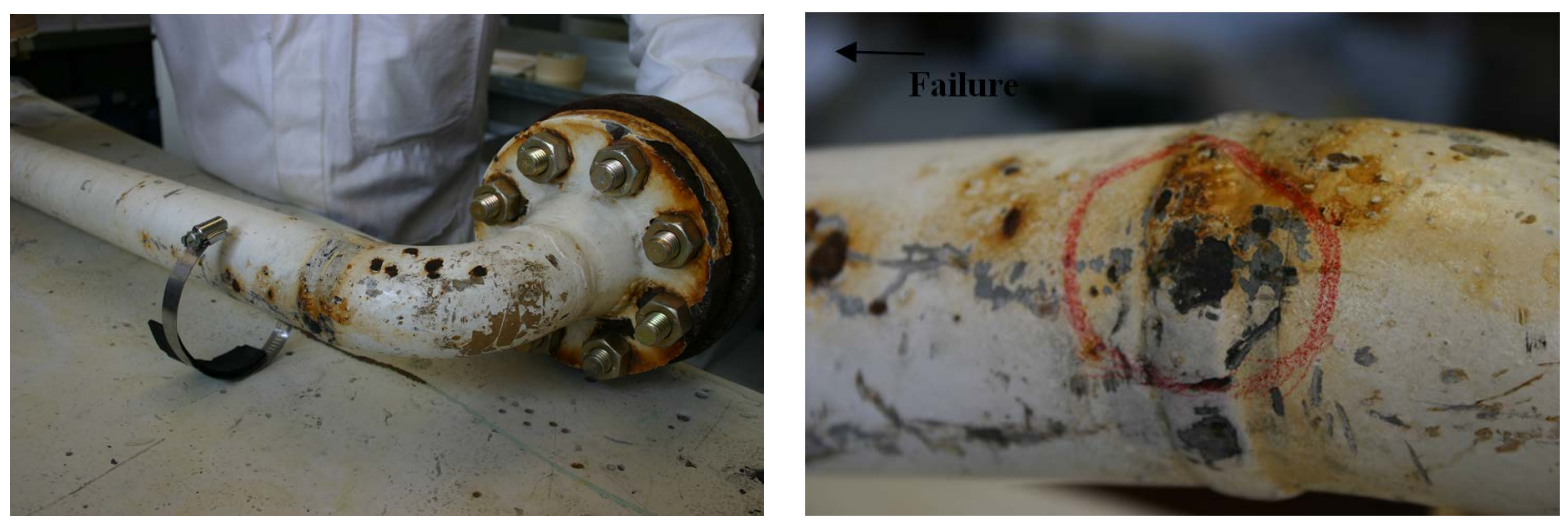

Figure 9. Location of the site where failure occurs.

ferent areas along the inner wall. SRB have been considered as the main agent for the microbiological induced corrosion occurring in hydrocarbon transport and distribution systems [12]-[14].

SRB presence was determined using culture media, according to API Recommended Practice No. 38 [15]. This is a specific culture for this kind of microorganisms.

When SRB are present in the samples, they reduce the sulfate of the media to sulfide, which reacts with iron to produce a black precipitate of iron sulfide. This is an indicative of SRB presence. When there is no presence of SRB, the culture media remains transparent with no change (Figure 10).

The formation of FeS deposits at the metal surface is one of the main characteristics of this type of corrosion. These results are in good agreement with those obtained in Stage 1, where the presence of SRB in water was indicated.

It is important to point out that the presence of SRB constitutes a risk for the integrity of metallic structures, as these microorganisms induce localized corrosion. Therefore, its identification and control becomes necessary.

\subsubsection{X-Ray Diffraction, X-Ray Fluorescence and Mössbauer Spectroscopy Analyses}

The corrosion products obtained from the metal surface were analyzed by different techniques: X-ray diffraction, X-ray fluorescence, and Mössbauer spectroscopy. The following was observed:

Mössbauer Spectroscopy: This analysis is specific to determine iron compounds. The spectrum obtained is shown in Figure 11. The compounds found mainly correspond to iron sulfides: Troilite (FeS), Mackinawite $\left(\mathrm{FeS}_{0.9}\right)$ and $\mathrm{FeS}_{2}$.

X-Ray Fluorescence: This technique is directed to establish the presence of chemical elements in the sample. The results indicate different elements, mainly S, Fe and O.

X-Ray Diffraction: Using this technique, the presence of diverse compounds with crystalline structure can be identified. The obtained diagram exhibited the following compounds: Mackinawite $\left(\mathrm{FeS}_{0.9}\right)$, Marcasite $\left(\mathrm{FeS}_{2}\right)$, Pyrite $\left(\mathrm{FeS}_{2}\right)$, Troilite (FeS) and Pyrrhotite (FeS).

According to theses analyses, it may be possible to establish that the main corrosion products formed at the inner metal surface are iron sulfides, which may result from:

- The presence of $\mathrm{H}_{2} \mathrm{~S}$ in the hydrocarbon and the associated water;

- The activity of SRB, which was identified in the system. Iron sulfide is a sub-product of the microorganism metabolism.

It is important to mention that although the X-ray fluorescence analysis indicated oxygen content, no oxides were identified by X-ray diffraction nor Mösbauer spectroscopy. In this way, it must be said that during the first inspection of the corrosion products at the metal surface, some "reddish" products characteristics for oxide compounds were observed. These red products were entrusted in the interstices of the inner metal wall, underneath the metal-corrosion products interface. For this reason, the oxides were not detected, even though its presence was visually corroborated.

\subsubsection{Surface Analysis}

Several surface analyses, using the Scanning Electron Microscope, were carried out at the site where the failure 


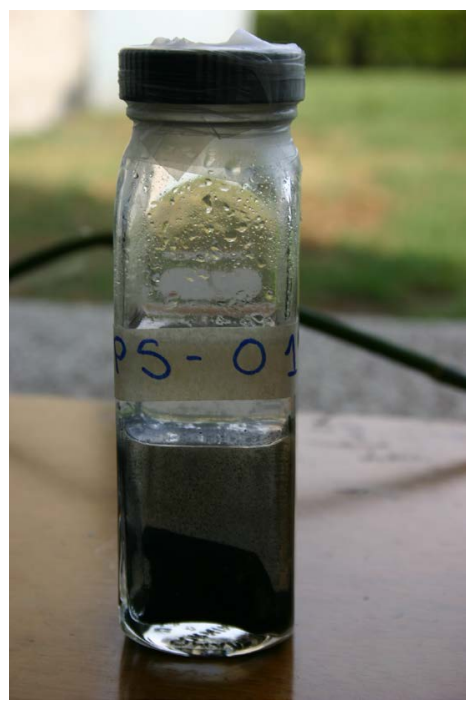

(a)

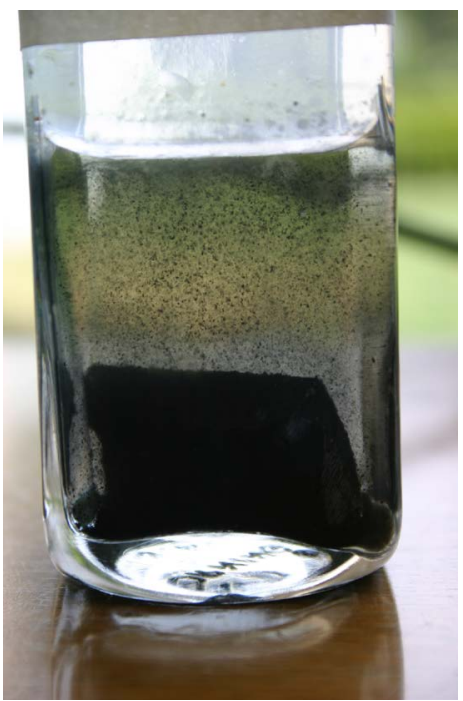

(b)

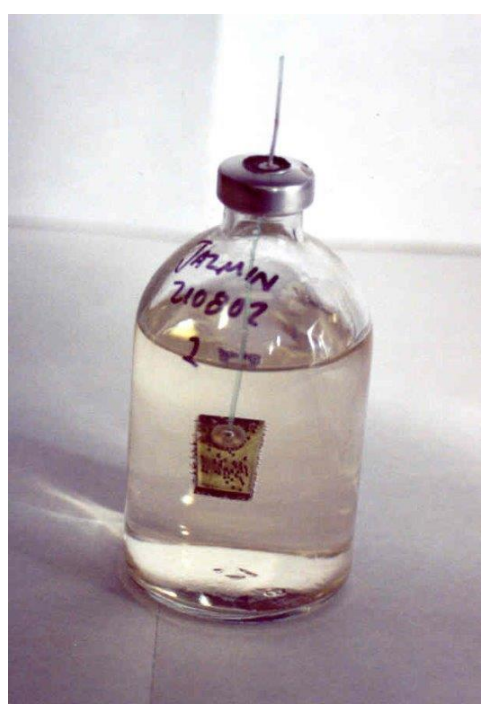

(c)

Figure 10. Presence of sulfate reducing bacteria, indicated by the formation of FeS deposits. a) Presence of SRB; b) Presence of SRB; c) Absence of SRB (Blank).

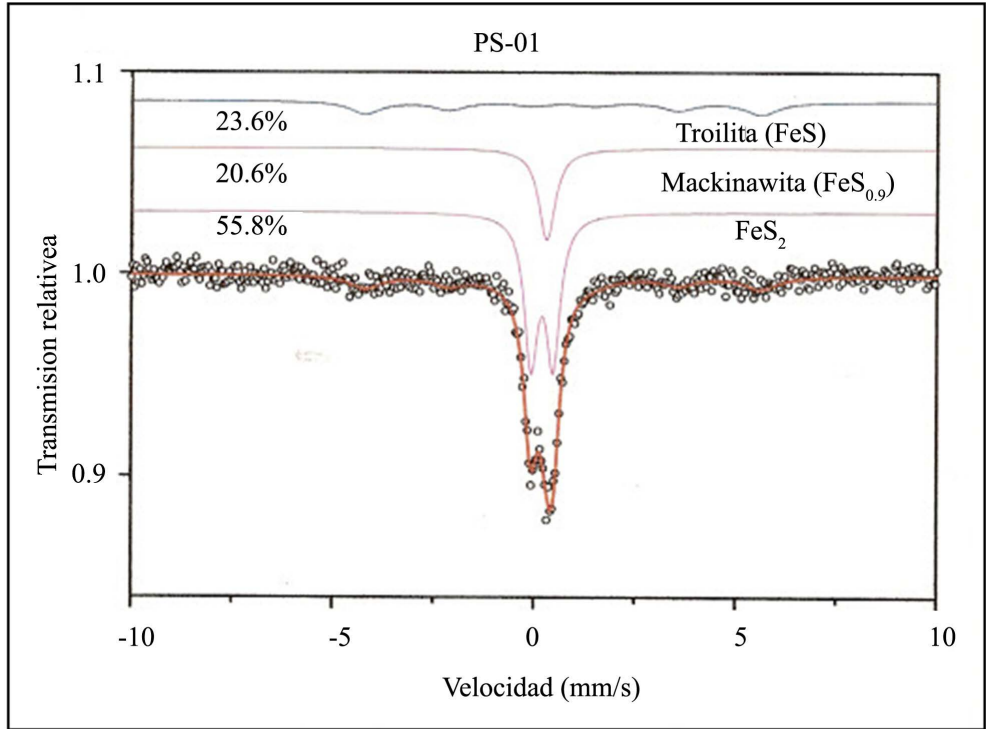

Figure 11. Spectrum obtained from Mössbauer spectroscopy.

occurred, before and after the corrosion products were removed from the metal surface [16]. The results corresponding to the analysis with corrosion products at the surface, exhibited a rectangular failure, with side dimensions of $253 \mu \mathrm{m}$ and $629 \mu \mathrm{m}$, located at the welding joint (Figure 12). An elemental analysis indicated a typical mild steel composition, including Fe, C, Ni, Cr, Si, and Mn.

Moreover, $\mathrm{S}$ and $\mathrm{O}$ were observed. These elements are associated to the steel composition, but also could be related to the corrosion products formed at the metal surface. Once the corrosion products were removed, a surface analysis was carried out. A uniform corrosion process was observed in the entire metal surface, with a type of localized corrosion in specific sites (Figure 13).

In this case, the characteristics elements for carbon steel are still observed. However, there is lower oxygen content and the presence of sulfur was detected. These results corroborate the fact that the corrosion products are mainly formed by sulfides and oxides. Additionally, as the failure occurred in a welding joint, a galvanic corrosion effect was considered and a metallographic analysis was suggested. 


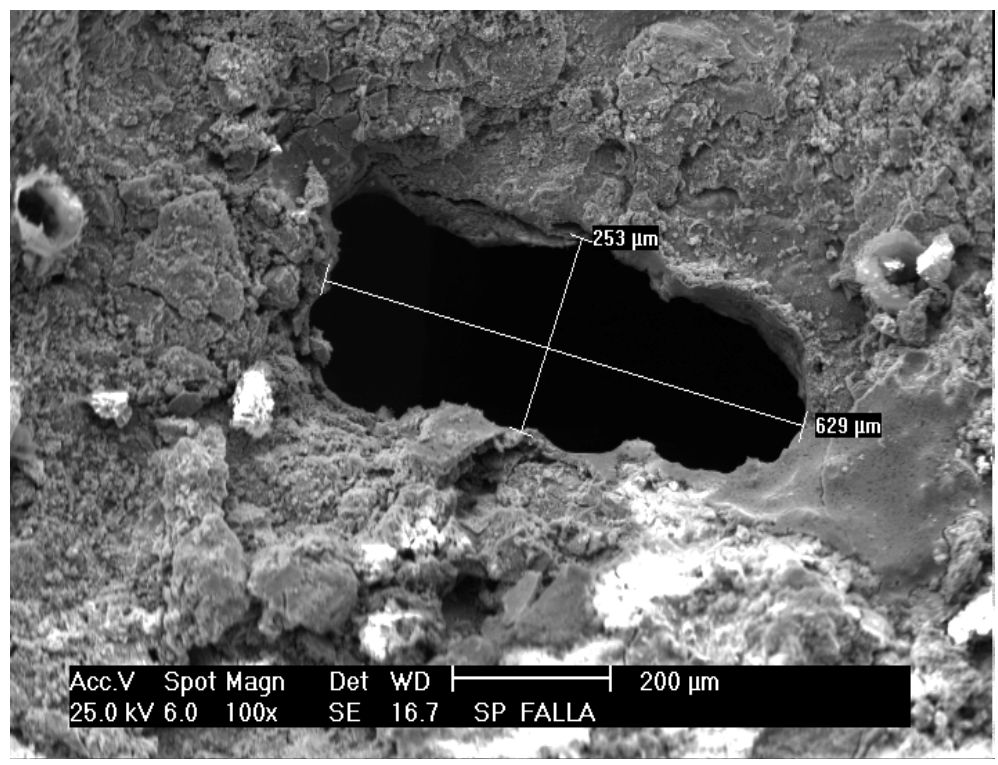

Figure 12. Micrograph of failure. Corrosion products at the metal surface.

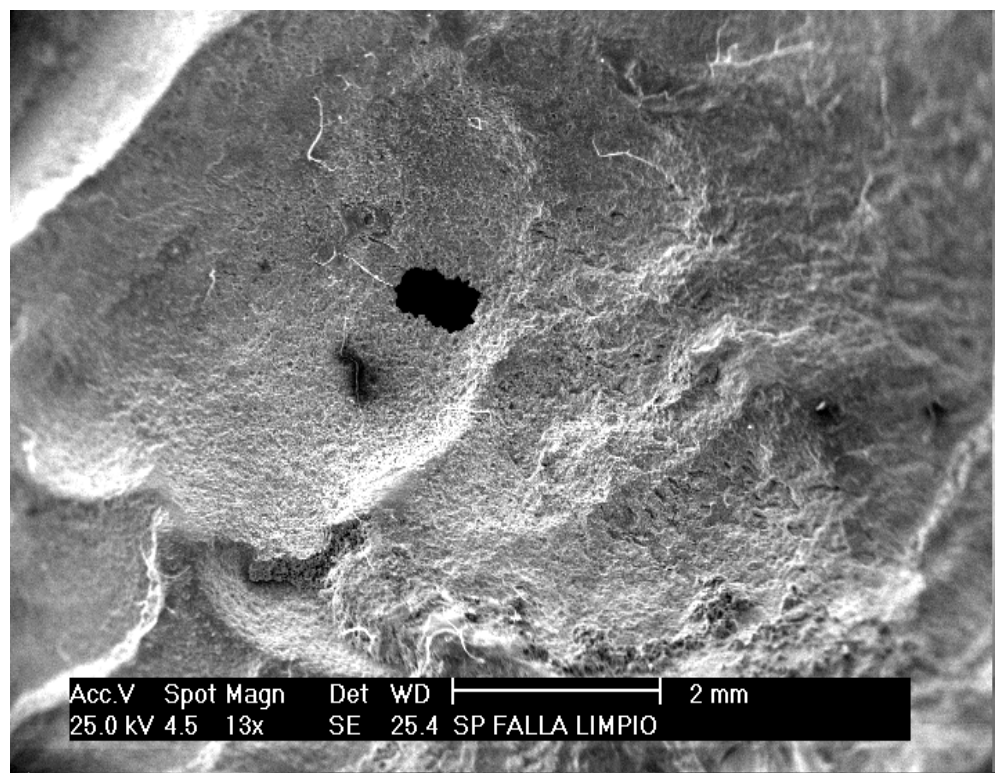

Figure 13. Micrograph of failure. Metal surface free of corrosion products.

\subsubsection{Metallographic Analysis}

A metallographic analysis and a hardness profile were carried out at the site where the failure occurred, considering the tube, the welding joint and the elbow. During the sample preparation, inclusions at the metal surface were evaluated. Sulfides and oxides were observed in the tube and oxides were noticed at the elbow surface. These results corroborate previous analysis, where the presence of these two compounds was reported. Regarding the hardness profile, the results indicate similar behavior for the three regions analyzed: tube, welding joint and elbow. Values around 74 Rockwell units (HRBW) were measured. However, the heat affected regions (HAR) exhibited higher hardness values, around $86 \mathrm{HRB}$, as shown in Figure 14.

On the other hand, according to the metallographic analysis, the tube-elbow microstructure arrangement indicated the presence of Pearlite and Ferrite, as shown in Table 1.

It is important to point out that the steel physical properties and its behavior depend mainly upon the carbon content and its distribution into the iron matrix. Most of the steels are a combination of three phases: pearlite, 


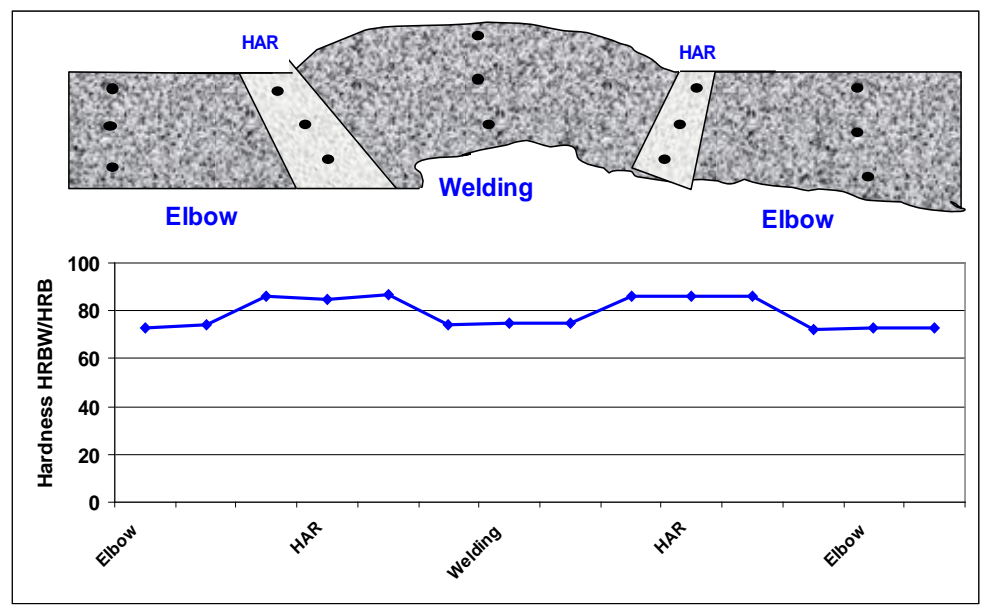

Figure 14. Hardness profile for the metal sample.

Table 1. Microstructures present in the materials.

\begin{tabular}{cc}
\hline Analysis Region & Microstructure \\
\hline Elbow & ${\text { Pearlite }+ \text { Ferrite }^{(\mathrm{a})}}^{\text {HAR }}$ \\
Welding joint & Proeutectoid pearlite + fine pearlite \\
HAR & Proeutectoid pearlite + dendrites \\
Tube & Proeutectoid pearlite + fine pearlite \\
Tube in corroded region & Pearlite + Ferrite \\
Elbow in corroded region & Pearlite + Ferrite \\
\hline
\end{tabular}

(a) Grain size 9; (b) Grain size 7 - 8

cementite and ferrite. The strength and hardness of steel with no heat treatment depend on the proportion of these three phases.

For this specific case, a typical carbon steel microstructure formed by ferrite and pearlite was observed for the tube and elbow. The welding joint material had a microstructure formed mainly by proeutectoid pearlite that can be considered as typical for low carbon steel. The presence of dendrites in the welding joint may be related to a material heat effect. The regions identified as HAR presented microstructures constituted mainly by proeutectoid pearlite and fine pearlite. The different microstructures shown by each region could indicate a galvanic effect that contributes to the corrosion process at the failure site, which also corresponds to the welding joint region.

\subsubsection{Chemical Analysis}

To complete the metallographic analysis and to identify any difference between the chemical composition of the tube, elbow and welding joint, a chemical analysis was carried out, using the Atomic Absorption Technique. This was done to determine the elements present in the metals and the results are summarized in Table 2. According to this table, the tube and elbow had similar chemical composition, indicating the same type of steel. However, the welding joint material presented some significant differences, mainly related to the content of Fe, C, Mn, Si and S.

A galvanic effect could be explained by these differences and the different microstructures observed in the metals. It seems that the welding joint material acts as an anode and the adjacent regions as a cathode.

\subsubsection{Corrosion Process Morphology}

The results obtained at this moment indicate that there are right conditions in the system for the development of a corrosion process in the inner wall of the pipeline. There is high water content, in addition to the presence of 
corrosive agents and appropriate material conditions. For the failure considered in this work, different corrosion processes were observed:

1) The first visual inspection of the pipeline inner wall, after the first metal cut and before any metal cleaning, indicated a severe uniform corrosion, identified by a reduction of the pipeline thickness in specific sites, mainly located at the 6 hours position (Figure 15).

This type of corrosion was generally observed at the elbows and " $T$ " joints, where the fluid changes its flow direction. It is expected that during the hydrocarbon transport, heavier fluids are located at the bottom of the pipeline. For this specific case, water phase is in this position, generating aggressive conditions for the metal.

Due to the morphology, location and distribution of this type of uniform corrosion, an erosion corrosion effect is considered. In this type of corrosion, the hydrocarbon flow is enough to remove corrosion products from the metal surface, decreasing their protective effect and increasing the corrosion rate. Corrosion processes due to fluids flow usually induced a localized impact pattern. The failure was located at the welding joint, in a site where an erosion corrosion effect was also observed, as shown in Figure 16.

In this way, it is very important to verify the fluid velocity, as it should not exceed the recommended material limits. From a corrosion point of view, a smooth flow is always preferable to a turbulent flow. At the same time, gases and solid particles must be eliminated from the fluid as possible.

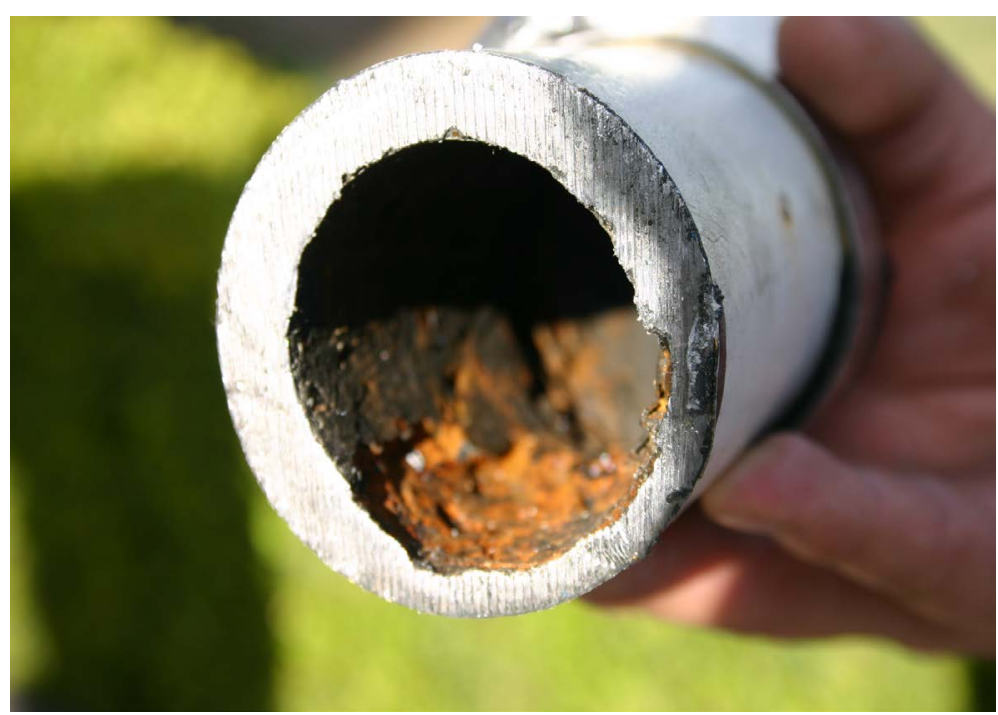

Figure 15. Pipeline transverse cutting. First elbow after the high pressure separator.

Table 2. Chemical composition of metal samples.

\begin{tabular}{cccc}
\hline \multirow{2}{*}{ Metal } & \multicolumn{3}{c}{ Chemical Composition } \\
\cline { 2 - 4 } Cr & Elbow (\%) & Welding joint (\%) & Tube (\%) \\
Mn & 0.03 & 0.05 & 0.03 \\
$\mathrm{Mo}$ & 0.79 & 1.19 & 0.92 \\
$\mathrm{Ni}$ & 0.02 & $<0.01$ & $<0.01$ \\
$\mathrm{Si}$ & 0.08 & 0.02 & 0.03 \\
$\mathrm{C}$ & 0.31 & 0.62 & 0.19 \\
$\mathrm{~S}$ & 0.195 & 0.043 & 0.163 \\
$\mathrm{P}$ & 0.003 & 0.024 & 0.002 \\
$\mathrm{Fe}$ & 0.018 & 0.023 & 0.022 \\
& 98.60 & 97.96 & 98.66 \\
\hline
\end{tabular}




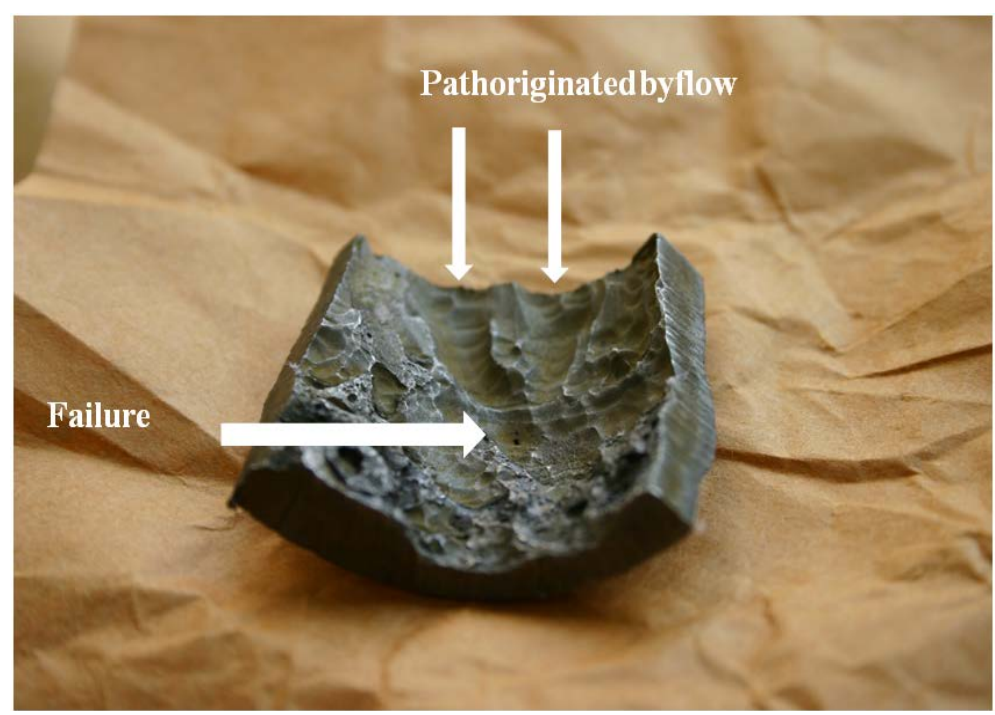

Figure 16. Site where failure occurs. Erosion corrosion goes in flow direction.

2) A galvanic corrosion process may be considered at the welding joints regions. This type of corrosion occurs because of potential differences between metallic materials, when in contact and in presence of an electrolyte. The material with more negative potential acts as an anode and exhibited a corrosion process. For this specific case, apparently the welding joint acted as anode in the corrosion reaction. However, the galvanic corrosion was less evident in the site where the failure occurred, because of the effect of the erosion corrosion. At the 12 technical hours position, the erosion corrosion effect is less evident and the galvanic corrosion is clearly observed (Figure 17).

3) Microbiological induced corrosion, which can be associated to localized corrosion processes, was observed along the metal sample. It was more evident at longitudinal regions, between 5 and 7 technical hours positions, although this type of corrosion was also detected in most of the pipeline inner metal surface, as shown in Figure 18. Corrosion products were removed from some pits and SRB populations were detected inside the cavities.

Additionally, microorganisms were also detected at the region where the failure occurred. This situation indicated that microbiological induced corrosion had also an effect on the metal failure, although the evidences were not clear, because of the presence of the other types of corrosion.

\section{Conclusions}

- The hydrocarbon condensed products transported by the 2 inches diameter steel pipeline, at the exit of the high pressure separator system, exhibited aggressive conditions for the inner metal wall. The main corrosive agents identified in the fluid are:

1) Water content;

2) The presence of dissolved gases $\left(\mathrm{H}_{2} \mathrm{~S}, \mathrm{CO}_{2}\right.$ and $\left.\mathrm{O}_{2}\right)$;

3) Microorganisms population, mainly sulfate reducing bacteria.

- The problem was considered as a combined effect of three types of corrosion:

1) Erosion corrosion, caused by the fluid flow and changes in the fluid direction;

2) Galvanic corrosion, mainly caused by differences in the chemical composition and microstructures of the metallic materials;

3) Microbiologically induced corrosion, caused by the presence of sulfate reducing bacteria.

- The corrosive agents in the system, such as $\mathrm{CO}_{2}, \mathrm{H}_{2} \mathrm{~S}$ and $\mathrm{O}_{2}$, participate in the cathodic reaction during the corrosion process.

- This type of failure occurs in characteristic sites of the pipelines path, mainly in direction changes and in welding joints.

- However, localized corrosion processes must also be considered. This type of corrosion does not follow a specific pattern, and becomes more important in sites where flow does not have influence. 


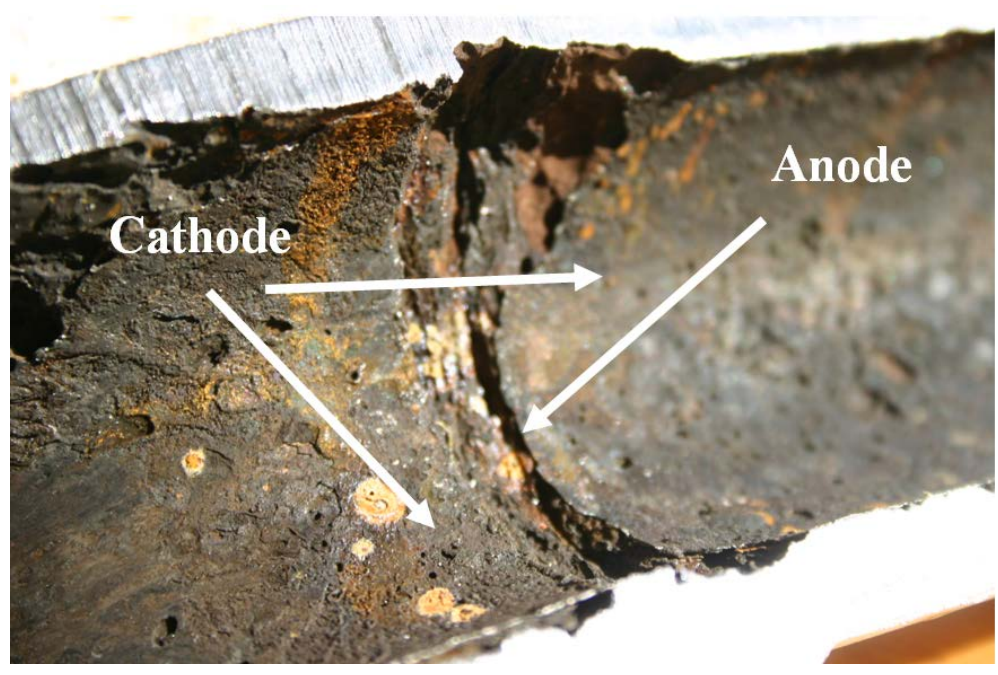

Figure 17. Corrosion process at the interface tube-elbow.
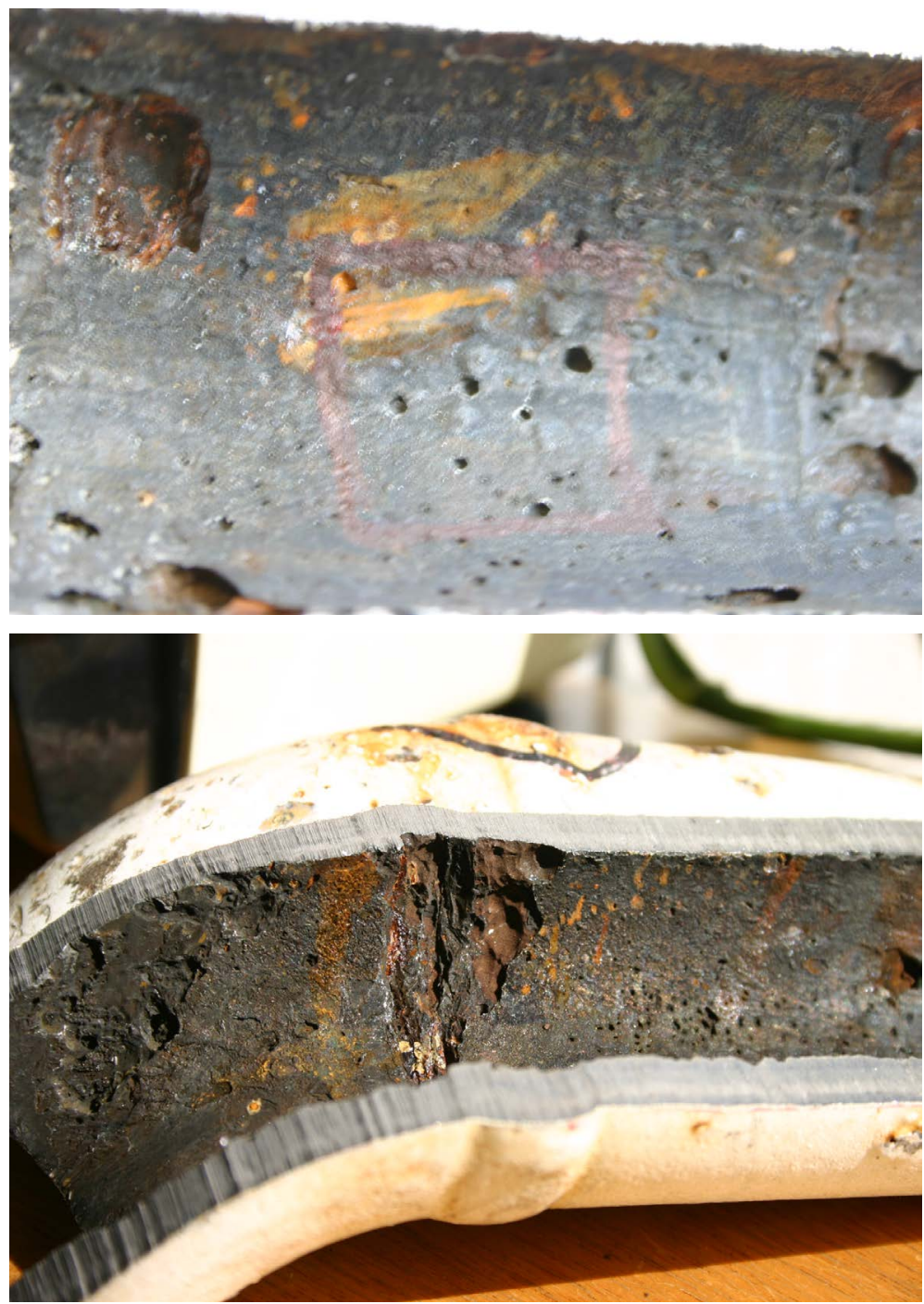

Figure 18. Localized corrosion at the elbow inner wall. 


\section{Recommendations}

The cause for the failure observed in the system is a combined effect of different corrosion types and therefore several actions must be considered:

1) To install an inhibitor injection system. The inhibitor considered must remove the oxygen in the system and form a film in the metal surface;

2) To consider a biocide injection program;

3) To verify the specifications of the system, relating to the hydrocarbon transport, in order to control the fluid flow, according to the separator system design;

4) To eliminate the water content, as it represents one of the main corrosive agents. A modification on the separation equipment should be considered;

5) To carry out a fluid quality control program;

6) To review the welding procedures, in order to eliminate any discontinuity in the inner pipeline wall;

7) To consider a heat treatment for stress relieve, after heat treatment;

8) To maintain a constant flow in the pipelines.

\section{References}

[1] (2006) NACE Standard SP0106-2006: Control of Internal Corrosion in Steel Pipelines and Piping Systems. NACE International, Houston.

[2] (1991) API RP 14E: Recommended Practice for Design and Installation of Offshore Production Platform Piping Systems. API, Washington DC.

[3] (2002) NACE Standard RP0102: In Line Inspection of Pipelines. NACE International, Houston.

[4] (2010) ASTM D 3370. Sampling Water from Closed Conduits.

[5] (2014) NACE Standard TM0194-2014: Field Monitoring of Bacterial Growth in Oil and Gas Systems. NACE International, Houston.

[6] (2012) ASTM D5504-12: Standard Test Method for Determination of Sulfur Compounds in Natural Gas and Gaseous Fuels by Gas Chromatography and Chemiluminescence.

[7] Pisigan Jr., R.A. and Singley, J.E. (1985) Evaluation of Water Corrosivity Using the Langelier Index and Relative Corrosion Rate Models. Materials Performance, 24, 26-36.

[8] Sastri, V.S. (1998) Corrosion Inhibitors, Principles and Applications. John Wiley and Sons, New York.

[9] Callister, W.D. (2000) Materials Science and Engineering: An Introduction. John Wiley and Sons, New York.

[10] Byars, H. (1999) Corrosion Control in Petroleum Production. 2nd Edition, NACE International, Houston.

[11] Atkinson, J.T.N. (1985) Corrosion and Its Control: An Introduction to the Subject. NACE International, Houston.

[12] (2002) ASTM D 4412-84: Standard Test Method for Sulfate Reducing Bacteria in Water Formed Deposits.

[13] Ghazy, E.A., Mahmoud, M.G., Asker, M.S., Mahmoud, M.N., Abo Elsoud, M.M. and Abdel Sami, M.E. (2011) Cultivation and Detection of Sulfate Reducing Bacteria (SRB) in Sea Water. Journal of American Science, 7, 604-608.

[14] (1995) ASTM F488-95: Standard Test Method for On-Site Screening of Heterotrophic Bacteria in Water.

[15] (1982) API Recommended Practice No. 38: Biological Analysis for Subsurface Injection Waters. API, Philadelphia.

[16] (2011) ASTM G1-03: Standard Practice for Preparing, Cleaning, and Evaluating Corrosion Test Specimens. 